\title{
Hydrogen Absorption into Austenitic Stainless Steels Under High-Pressure Gaseous Hydrogen and Cathodic Charge in Aqueous Solution
}

\author{
MASATO ENOMOTO, LIN CHENG, HIROYUKI MIZUNO, YOSHINORI WATANABE, \\ TOMOHIKO OMURA, JUN'ICHI SAKAI, KEN'ICHI YOKOYAMA, HIROSHI SUZUKI, \\ and RYUJI OKUMA
}

Type 316L and Type 304 austenitic stainless steels, both deformed and non-deformed, were hydrogen charged cathodically in an aqueous solution as well as by exposure to high-pressure gaseous hydrogen in an attempt to identify suitable conditions of cathodic charge for simulating hydrogen absorption from gaseous hydrogen environments. Thermal desorption analysis (TDA) was conducted, and the amount of absorbed hydrogen and the spectrum shape were compared between the two charging methods. Simulations were performed by means of the McNabb-Foster model to analyze the spectrum shape and peak temperature, and understand the effects of deformation on the spectra. It was revealed that the spectrum shape and peak temperature were dependent directly upon the initial distribution of hydrogen within the specimen, which varied widely according to the hydrogen charge condition. Deformation also had a marked effect on the amount of absorbed hydrogen in Type 304 steel due to the straininduced martensitic transformation.

DOI: $10.1007 / \mathrm{s} 40553-014-0034-5$

(C) ASM International (ASM) and The Minerals, Metals, \& Materials Society (TMS) 2014

\section{INTRODUCTION}

HydroGEN is a clean energy source which has the potential to be widely used in various energy systems in the near future. Fuel cell vehicles equipped with cylinders containing high-pressure hydrogen gas up to $70 \mathrm{MPa}$ will be commercialized within a few years, and hydrogen stations which supply fuel cell vehicles with gaseous hydrogen are under construction. ${ }^{[1]}$ The safe use and public acceptance of compressed hydrogen gas are important issues for the developments of hydrogen systems.

MASATO ENOMOTO, Emeritus Professor, is with Ibaraki University, Nakanarusawa, Hitachi 316-8511, Japan. Contact e-mail: enomotom@mx.ibaraki.ac.jp LIN CHENG, Lecturer, is with the International Research Institute of Steel Technology, Wuhan University of Science and Technology, Wuhan 430081, P.R. China. HIROYUKI MIZUNO, Senior Chief of Staff, and YOSHINORI WATANABE, Staff, are with the Technical Development Div., Aichi Steel Corporation, Arao-machi, Tokai-shi, Aichi-ken 476-8666, Japan. TOMOHIKO OMURA, Chief Researcher, is with the Steel Research Laboratory, Nippon Steel \& Sumitomo Metal Corporation Fuso-cho, Amagasaki 660-0891, Japan. JUN'ICHI SAKAI, Professor, is with the Faculty of Science \& Engineering, Waseda University, Ohkubo, Shinjuku-ku, Tokyo 162-8244, Japan. KEN'ICHI YOKOYAMA, Associate Professor, is with the Department of Materials Science and Engineering, Kyushu Institute of Technology, Sensui-cho, Tobata-ku, Kitakyushu 804-8550, Japan. HIROSHI SUZUKI, Associate Professor, is with the Department of Engineering and Applied Sciences, Faculty of Science and Technology, Sophia University, Kioi-cho, Chiyoda-ku, Tokyo 102-8554, Japan. RYUJI OKUMA, Senior Staff, is with the Solid Analysis Group, Sumika Chemical Analysis Service, Ltd., Sodegaura, Chiba 299-0266 Japan.

Manuscript submitted February 9, 2014.

Article published online October 21, 2014
However, it is well known that high-pressure hydrogen gas degrades mechanical properties of many kinds of metallic materials, which are used for the storage and transportation of hydrogen. ${ }^{[2-4]}$ The environmental degradation in gaseous hydrogen is called hydrogen environment embrittlement (HEE) or hydrogen gas embrittlement (HGE), which occurs when a hydrogen-free material is mechanically tested in gaseous hydrogen at ambient temperature. HGE is recognized as one type of hydrogen embrittlement (HE) caused by hydrogen entry into metallic materials from gaseous hydrogen environments. Thus, effects of gaseous hydrogen on tensile or fatigue properties of several candidate materials have been the subject of keen interest in the past. ${ }^{[-11]} \mathrm{Up}$ to now, it was reported that metals with a face-centered cubic (fcc) structure such as stable austenitic stainless steels, e.g., Type $316 \mathrm{~L}$ or aluminum alloys, are not susceptible to HGE ${ }^{[5-9]}$ Because the assessment of $\mathrm{HGE}$ needs special testing equipment capable of controlling extremely high-pressure gaseous hydrogen, the limited availability of such testing equipment hampers is a serious obstacle to the collection of a large amount of test data necessary for establishing standards and regulations for hydrogen storage materials.

Cathodic hydrogen charge in an aqueous solution is a convenient test method to assess HE. Indeed, a large amount of data has been reported with respect to tensile properties of metals under cathodic charge in acidic solutions with catalysts which promote hydrogen entry into the materials. Hence, cathodic charging tests can be a convenient alternative to evaluate HGE. However, there are a limited number of studies regarding the relationship between HGE and embrittlement in an aqueous solution. It is reported that the degrees of 
Table I. Chemical Composition of Alloys Studied (mass pet)

\begin{tabular}{lcccccrrrr}
\hline Alloys & $\mathrm{C}$ & $\mathrm{Si}$ & $\mathrm{Mn}$ & $\mathrm{P}$ & $\mathrm{S}$ & $\mathrm{Ni}$ & $\mathrm{Cr}$ & $\mathrm{Mo}$ & $\mathrm{N}$ \\
\hline Type 304 & 0.060 & 0.4 & 1.1 & 0.028 & 0.003 & 8.0 & 18.1 & 0.1 & 0.035 \\
Type 316L & 0.007 & 0.5 & 0.9 & 0.027 & 0.001 & 12.2 & 17.5 & 2.0 & 0.013 \\
\hline
\end{tabular}

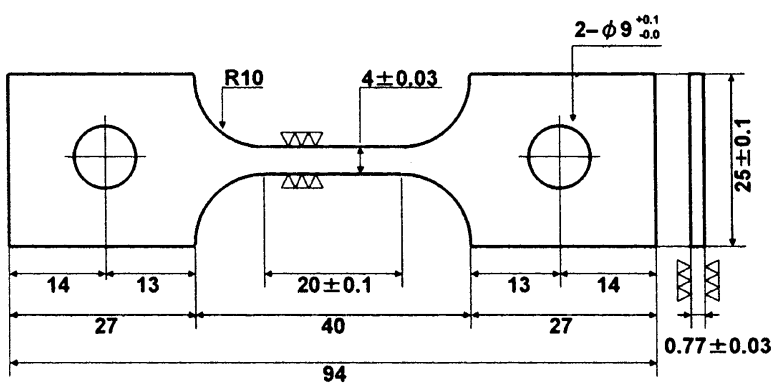

Fig. 1-Configuration and dimensions (in $\mathrm{mm}$ ) of specimen for tensile test.

mechanical degradation of the tensile properties under cathodic charge and high-pressure gaseous hydrogen are similar for Type 316L and 304L austenitic stainless steels. ${ }^{[12]}$

In this study, to explore the suitable conditions of cathodic charge for simulating hydrogen absorption from high-pressure gaseous hydrogen, Type 316L and Type 304 austenitic stainless steels, both deformed and non-deformed, were hydrogen charged cathodically and by exposure to high-pressure gaseous hydrogen. It is well known that thermal desorption analysis (TDA) is a useful tool to analyze the diffusion and trapping of hydrogen in the material which is thought to be closely related to HE. Hence, TDA was conducted to compare the amount of absorbed hydrogen and TDA spectrum shape between the two charging methods. Furthermore, simulations were performed using the McNabb-Foster model to analyze in detail the differences between the steels in the TDA spectrum shape and peak temperature, defined as the temperature at which the hydrogen desorption rate passes through a maximum, and understand the effects of deformation on hydrogen absorption. It will be shown that TDA spectra in stainless steel vary widely with the distribution of hydrogen prior to the analysis, and this has to be taken into account in establishing the relationship between different hydrogen charging methods, which are usually performed under different conditions with respect to hydrogen pressure, temperature, and time.

\section{EXPERIMENTAL PROCEDURE}

Commercial Type 304 and 316L stainless steels, cold rolled to $0.77-\mathrm{mm}$-thickness sheet and annealed above $1273 \mathrm{~K}\left(1000{ }^{\circ} \mathrm{C}\right)$, were used in this study. Table I shows the chemical composition of the alloys studied. In order to investigate the effects of deformation on hydrogen absorption, tensile specimens whose configuration

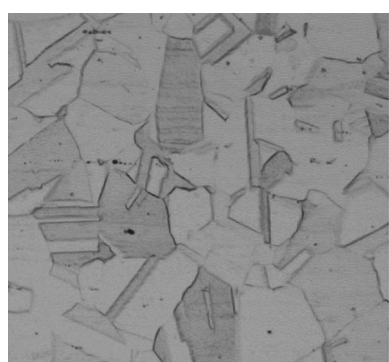

(a)

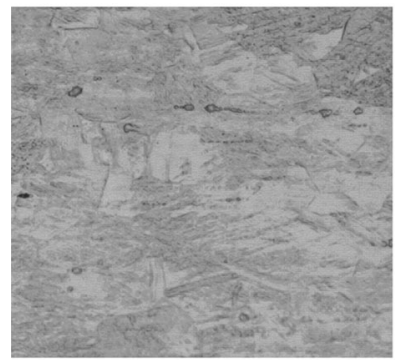

(c)

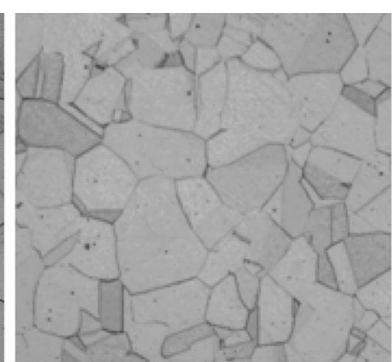

(b)

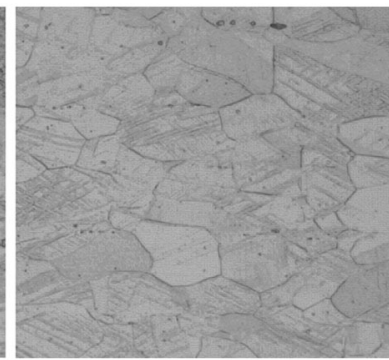

(d) $25 \mu \mathrm{m}$
Fig. 2-Optical micrograph of (a) non-strained Type 304 steel, $(b)$ non-strained Type $316 \mathrm{~L}$ steel, (c) 40 pct strained Type 304 steel, and (d) 40 pct strained Type 316L steel specimens.

is given in Figure 1 were machined from the sheet. They were deformed in tension to a strain of 10 and 40 pct. These specimens were polished and etched in aqua regia (a mixture of 3 hydrochloric acid and 1 nitric acid) for microstructural observation. Figures 2(a) through (d) show the optical micrographs of non-strained and 40 pct strained specimens of the two steels. The microstructure of non-strained specimens consists of polygonal austenite grains with annealing twins, while grains are somewhat elongated along the tensile direction in the 40 pct strained specimens.

The microstructure of Type 304 stainless steel is metastable austenite. The formation of martensite was detected by both X-ray diffractometry using Co $\mathrm{K}_{\alpha}$ radiation and magnetic measurement: the relative permeability, i.e., ratio of the permeability of specimen to vacuum, was measured using the so-called $\mu$-meter (LP141, Denshijiki Industry Co., Ltd) in which the contact probe detects a shift in the magnetic field lines in the applied magnetic field. The XRD spectra in Figure 3 indicate the formation of strain-induced martensite in the 40 pct strained Type 304 steel. In the 10 pet strained specimen, the strain-induced martensitic transformation was not detected by the measurement of permeability, either, as shown in Figure 4.

Hydrogen charge was conducted by two methods. One was exposure to gaseous hydrogen, and the other was 


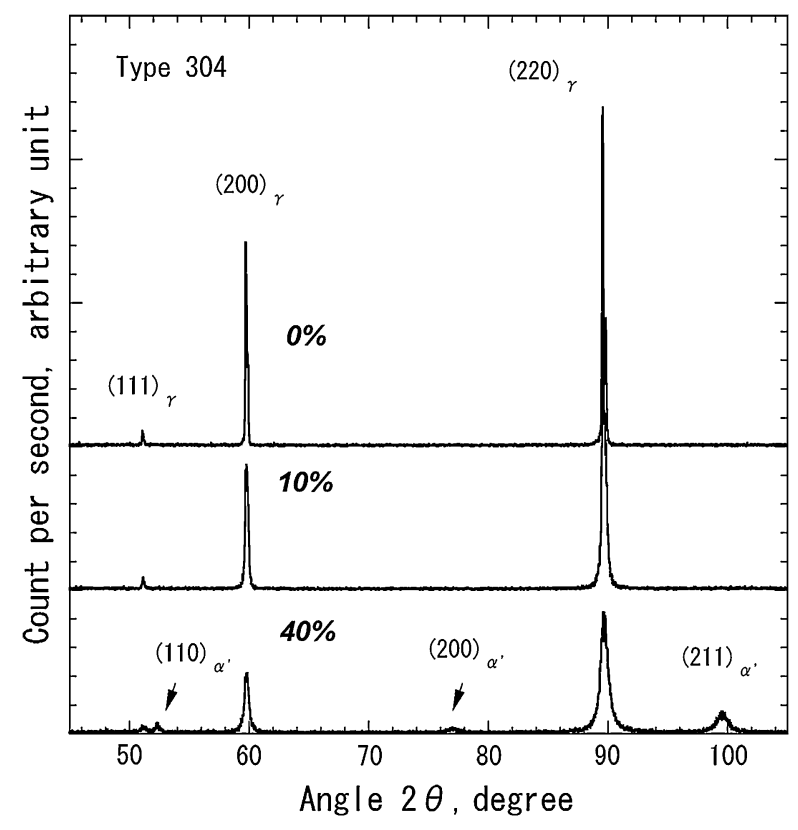

Fig. 3-XRD profiles of Type 304 stainless steel deformed in tension to a strain of 0,10 , and 40 pet.

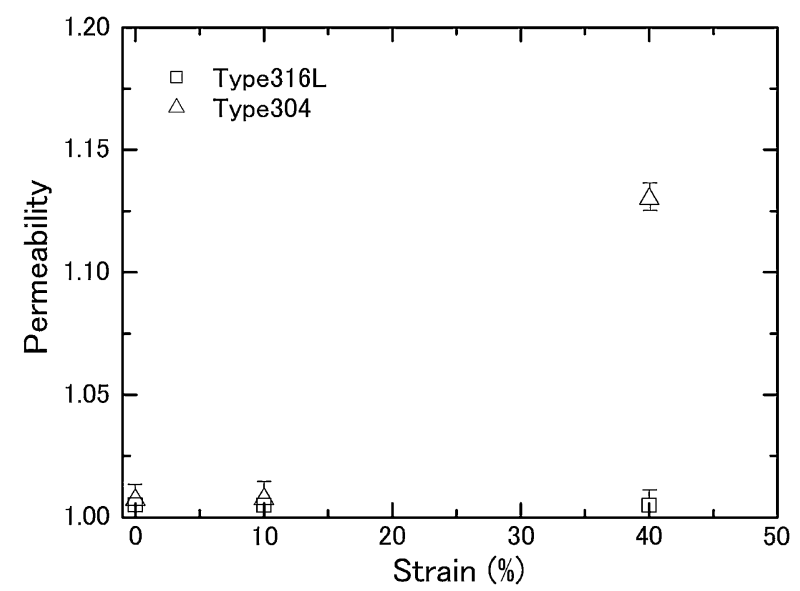

Fig. 4-Permeability of Type 304 and 316L steels plotted against tensile strain. The error range is \pm 0.01 .

cathodic electrolysis. The apparatus used for exposure to high-pressure hydrogen is illustrated in Figure 5(a). It can simulate the gaseous environment of high-pressure hydrogen in the container of fuel cell vehicle and hydrogen station. Table II shows the condition of exposure to gaseous hydrogen. According to the preliminary estimate, it is assumed in Condition 1, i.e., exposure to hydrogen atmosphere of $98 \mathrm{MPa}$ at $523 \mathrm{~K}\left(250{ }^{\circ} \mathrm{C}\right)$ for 72 hours, that absorbed hydrogen is distributed uniformly from the surface to the center of specimen. In contrast, Condition 2, exposed at $358 \mathrm{~K}\left(85^{\circ} \mathrm{C}\right)$ for 1000 hours, which is supposed to represent the condition of practical use, assumes that the absorbed hydrogen concentration is non-uniform, high near the surface of specimen and low in the central region. The electrolysis cell used for cathodic charge is illustrated in Figure 5(b).

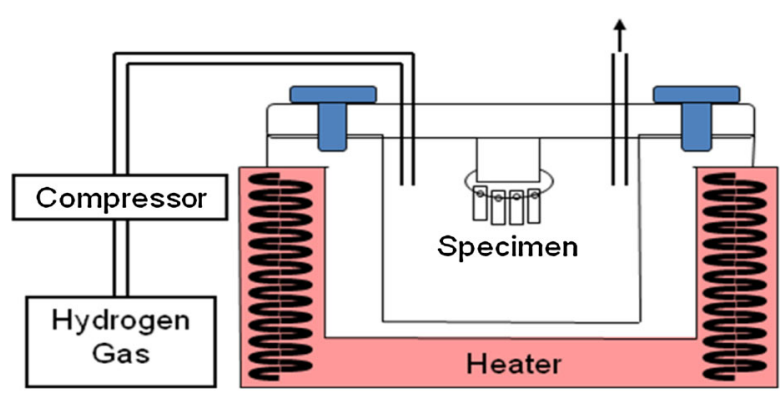

(a)

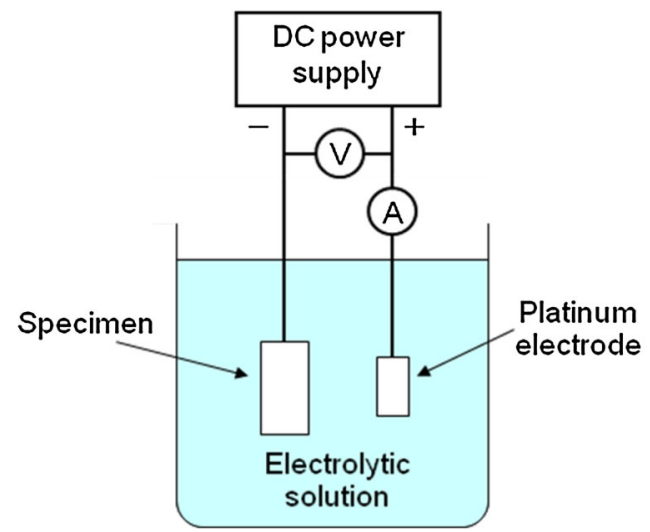

(b)

Fig. 5- Schematic illustration of apparatus for hydrogen charge (a) under high-pressure hydrogen and $(b)$ cathodic electrolysis.

Table II. Pressure and Temperature of Gaseous Hydrogen Used for Exposure of Specimen

\begin{tabular}{lccc}
\hline Condition & $\begin{array}{c}\text { Pressure } \\
(\mathrm{MPa})\end{array}$ & $\begin{array}{c}\text { Temperature } \\
{\left[\mathrm{K}\left({ }^{\circ} \mathrm{C}\right)\right]}\end{array}$ & $\begin{array}{c}\text { Exposure } \\
\text { Time }(\mathrm{h})\end{array}$ \\
\hline No. 1 & 98 & $523(250)$ & 72 \\
No. 2 & 98 & $358(85)$ & 1000 \\
\hline
\end{tabular}

This charging method is widely used because the amount of charged hydrogen can be controlled relatively easily. Here, cathodic charge was conducted at a constant electric current of $1 \mathrm{~mA} / \mathrm{cm}^{2}$ for 96 hours in an aqueous solution of 3 mass pet $\mathrm{NaCl}$ with the addition of $3 \mathrm{~g} / \mathrm{L}$ $\mathrm{NH}_{4} \mathrm{SCN}$. The parallel part, $20 \mathrm{~mm}$ in length, $4 \mathrm{~mm}$ in width, and $0.77 \mathrm{~mm}$ in thickness, cut from the hydrogencharged specimen was subjected to TDA using a gas chromatograph or a quadrupole mass spectrometer at a heating rate of $100 \mathrm{~K} / \mathrm{h}$.

\section{RESULTS}

\section{A. Exposure to Gaseous Hydrogen at $523 \mathrm{~K}\left(250^{\circ} \mathrm{C}\right)$} for 72 hours

Figures 6(a) and (b) show TDA spectra of Type 304 and $316 \mathrm{~L}$ steels, respectively, exposed to gaseous hydrogen under Condition 1. It is seen that all spectra exhibit 


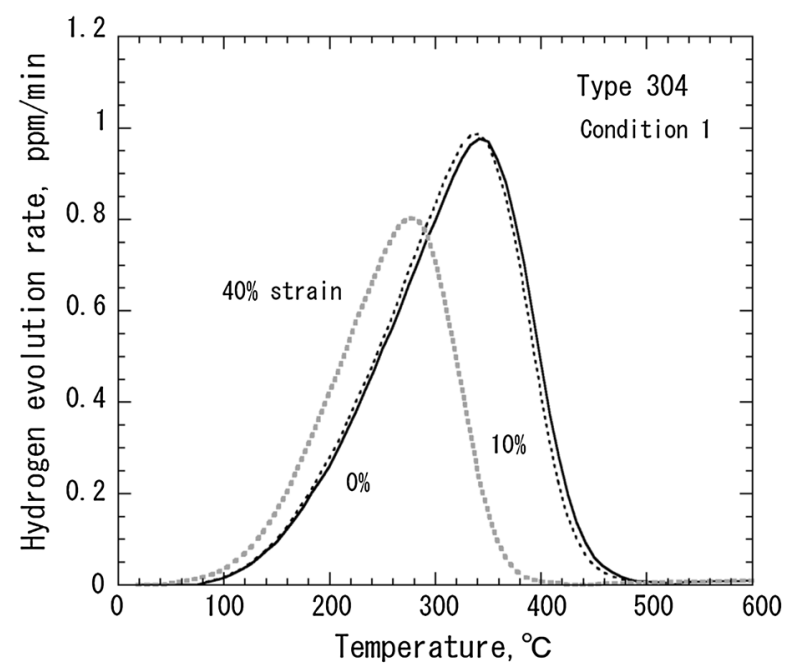

(a)

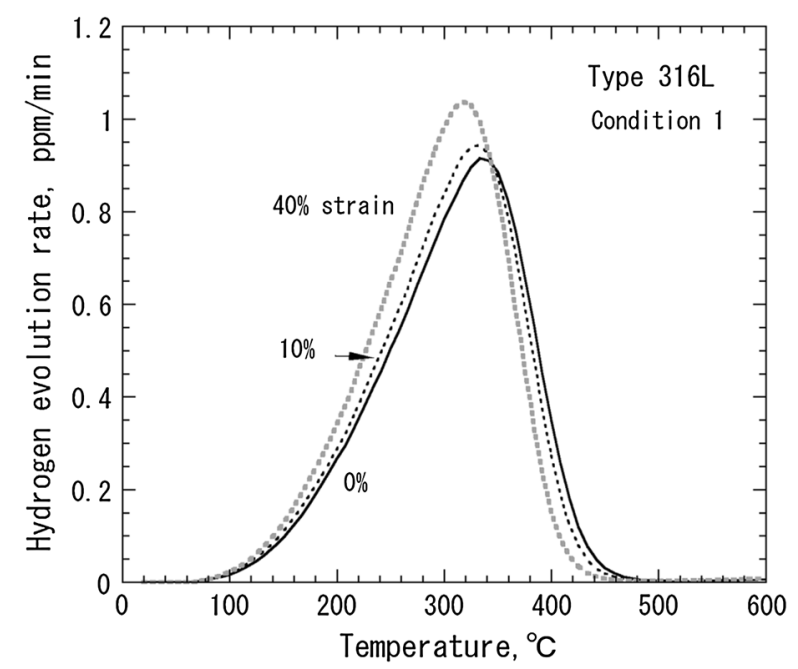

(b)

Fig. 6-TDA spectra of (a) Type 304 and (b) Type 316L steels exposed to gaseous hydrogen under Condition 1.

single desorption peaks no matter whether specimens are deformed or not. The desorption peak of the $40 \mathrm{pct}$ strained Type 304 steel is considerably lower and is located at a temperature $60 \mathrm{~K}$ to $70 \mathrm{~K}$ lower than the specimens of no-strain and 10 pct strained. In contrast, the desorption peak of Type $316 \mathrm{~L}$ steel specimen is higher, and the difference in temperature from the other two specimens is only $20 \mathrm{~K}$ to $30 \mathrm{~K}$.

In Figure 7, the desorption spectrum area, i.e., the amount of evolved hydrogen expressed in the mass fraction ( $\mathrm{ppm})$ of hydrogen in the specimen, is plotted against tensile strain. Although the increase in the amount of absorbed hydrogen in the 40 pct strained Type $316 \mathrm{~L}$ specimen is not significant, it is clear that deformation decreased the peak area in Type 304 steel. It is tentatively proposed that the decrease in the peak area of 40 pet strained Type 304 steel is caused by the formation of martensite upon deformation, as will be discussed later.

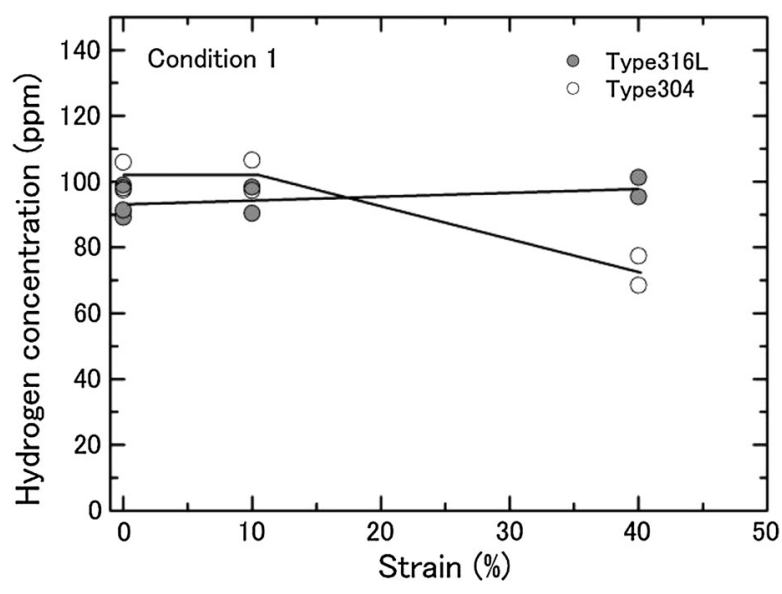

Fig. 7-Variation with tensile strain of peak area of Type 304 and 316L steels exposed to gaseous hydrogen under Condition 1.

\section{B. Exposure to Gaseous Hydrogen at $358 \mathrm{~K}\left(85^{\circ} \mathrm{C}\right)$ for $1000 \mathrm{~h}$}

TDA spectra of Type 304 and 316L specimens exposed to gaseous hydrogen under Condition 2 are shown in Figures 8(a) and (b), respectively. In Figure 8(a), only the spectrum of 40 pct strained Type 304 specimen has a single peak. The spectra of the other specimens have a broad peak which could be divided into two flat peaks. On the other hand, in Figure 8(b), the spectra of all three specimens have broad peaks in Type 316L steel. Figure 9 shows the variation of peak area with tensile strain. It is seen that the peak area increased with tensile strain in Type 304 steel, while no appreciable change is observed in the other steel. These are contrary to the results obtained under charging Condition 1.

\section{Cathodic Electrolysis}

Figures 10(a) and (b) show TDA spectra of Type 304 and 316L specimens, respectively, which were cathodically charged. The peak desorption temperature is around $373 \mathrm{~K}\left(100{ }^{\circ} \mathrm{C}\right)$ in all specimens. However, there is a sharp increase in the peak height with tensile strain in the former steel, while the increase in peak area is small in Type $316 \mathrm{~L}$ steel. The TDA spectrum peak area is plotted against tensile strain in Figure 11. A marked increase in the peak area is observed in the 40 pct strained Type 304 steel, while only a very moderate increase is observed in Type $316 \mathrm{~L}$ steel. These changes in peak area with strain are similar in sign, but occurred to a greater extent than those in Condition 2. This is tentatively ascribed to the inhomogeneous initial distribution of hydrogen caused by insufficient charging time.

\section{SIMULATION OF TDA SPECTRA BY McNABB-FOSTER MODEL}

\section{A. Non-deformed Specimen Charged Under High- Pressure Atmosphere}

According to $\mathrm{McNabb}$ and Foster, ${ }^{[13]}$ the diffusion and trapping of hydrogen in metallic materials can be described by the following equations: 


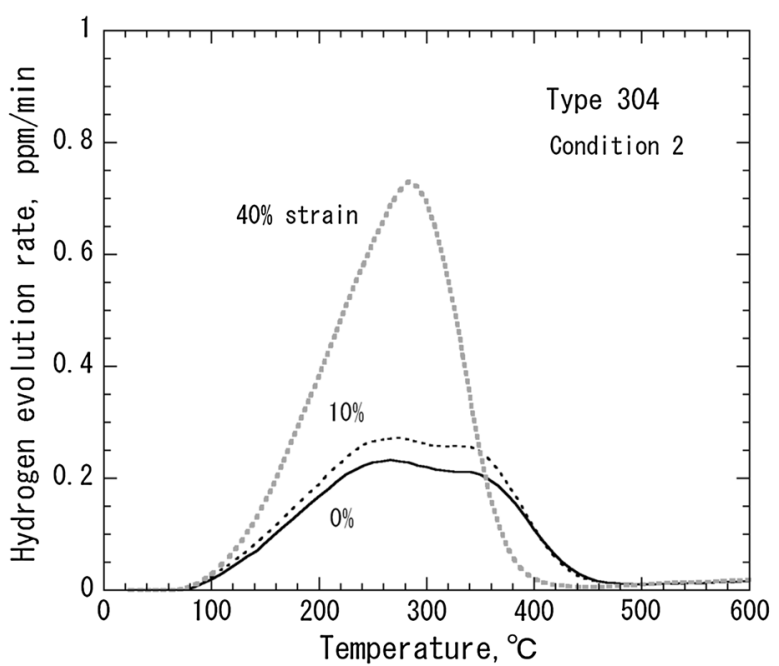

(a)

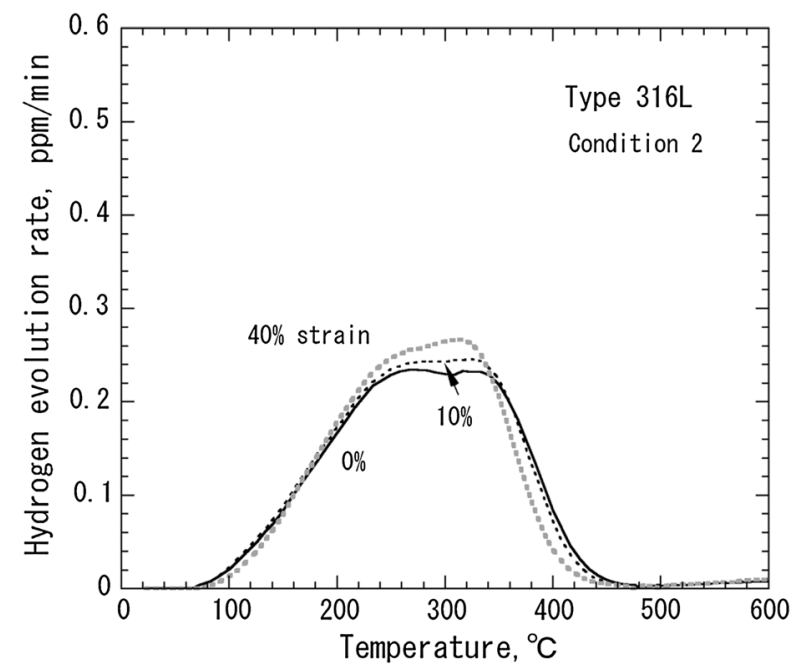

(b)

Fig. 8-TDA spectra of (a) Type 304 and (b) Type 316L specimens exposed to gaseous hydrogen under Condition 2.

$$
\begin{gathered}
\frac{\partial c}{\partial t}+N_{\mathrm{t}} \frac{\partial \theta_{\mathrm{t}}}{\partial t}=D \nabla^{2} c, \\
\frac{\partial \theta_{\mathrm{t}}}{\partial t}=k c\left(1-\theta_{\mathrm{t}}\right)-p \theta_{\mathrm{t}},
\end{gathered}
$$

where $c$ is the hydrogen concentration in the lattice, $N_{\mathrm{t}}$ is the density of trap sites, $\theta_{\mathrm{t}}$ is the occupancy fraction at the trap site, $D$ is the diffusivity of hydrogen in the normal lattice,

$$
k=k_{0} \exp \left(-\frac{E_{\mathrm{D}}}{R T}\right)
$$

and

$$
p=p_{0} \exp \left(-\frac{E_{\mathrm{d}}}{R T}\right)=p_{0} \exp \left(-\frac{E_{\mathrm{B}}+E_{\mathrm{D}}}{R T}\right)
$$

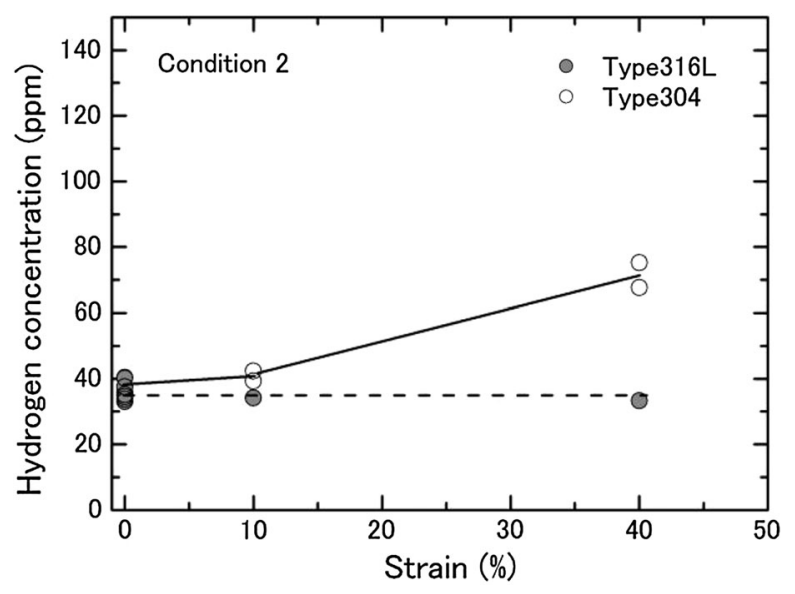

Fig. 9-Variation with tensile strain of peak area of Type 304 and 316L steels exposed to gaseous hydrogen under Condition 2.

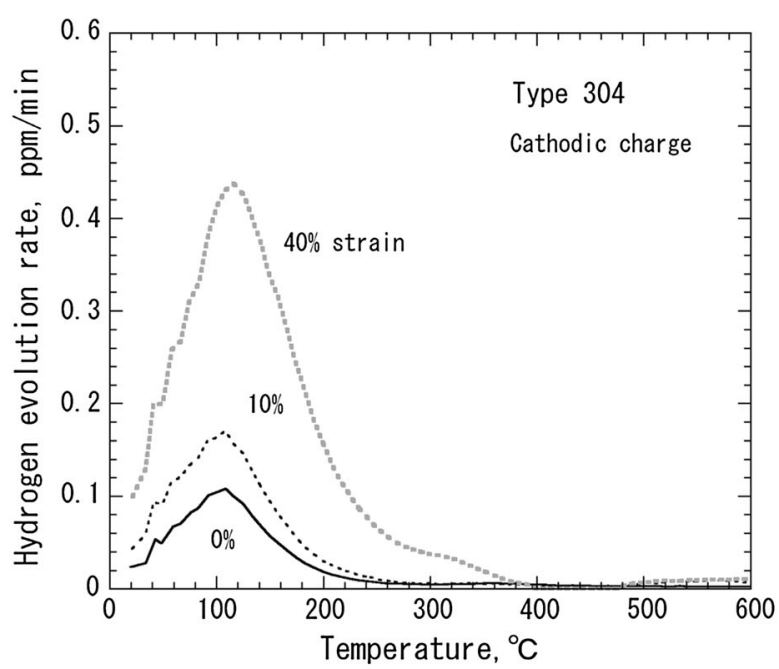

(a)

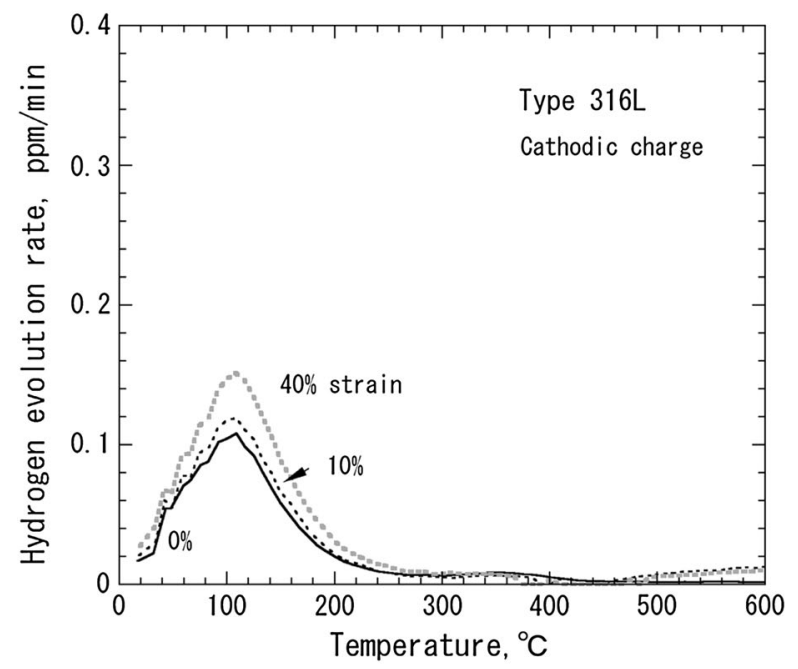

(b)

Fig. 10 - TDA spectra of cathodically charged (a) Type 304 and (b) Type $316 \mathrm{~L}$ specimens. 
are the kinetic coefficients of trapping and detrapping, respectively. Here, $E_{\mathrm{D}}$ is the activation energy of lattice diffusion and $E_{\mathrm{B}}$ is the binding energy of the trap site. $E_{\mathrm{d}}$ ( $\left.=E_{\mathrm{B}}+E_{\mathrm{D}}\right)$ is the activation energy of detrapping. $k_{0}$ and $p_{0}$ are related to each other as $k_{0}=p_{0} / N_{\mathrm{V}}{ }^{114]}$ where $N_{\mathrm{V}}\left(=8.77 \times 10^{28} \mathrm{~m}^{-3}\right)$ is the number of available sites of hydrogen in the fcc lattice per unit volume. Table III shows the activation energy and the pre-exponential factor of diffusivity of hydrogen in Type 304 and 316L steels reported in the literature.

Since the fraction of hydrogen in the trap sites is expected to be small in austenitic stainless steel due to the small binding energy of hydrogen to dislocations, the above equations were solved assuming $N_{\mathrm{t}}=0$ for specimens without tensile strain. Figures 12(a) and (b) show the TDA spectra of hydrogen in Type 304 and $316 \mathrm{~L}$ specimens exposed to a hydrogen atmosphere of $98 \mathrm{MPa}$ (Condition 1), calculated assuming the surface concentration of hydrogen equal to $100 \mathrm{ppm}$. The hydrogen concentration at the specimen surface was determined by trial and error comparing the whole area between simulated and experimental TDA spectra. Diffusivities reported by Sakamoto and Katayama $(\mathrm{S}-\mathrm{K})^{[15]}$ and Mine and Kimoto $(\mathrm{M}-\mathrm{K})^{[16]}$ were used for the Type 304 steel McNabb-Foster model calculations. For the Type $316 \mathrm{~L}$ calculations, diffusivities published by Brass and Chene $(\mathrm{B}-\mathrm{C})^{[17]}$ and Tanabe and Imoto $(\mathrm{T}-\mathrm{I})^{[18]}$ were employed. If one employs these diffusivities, the hydrogen distribution is uniform all over both specimen types under Condition 1. It is seen in Figure 12 that the $\mathrm{S}-\mathrm{K}$ and $\mathrm{B}-\mathrm{C}$ diffusivities can

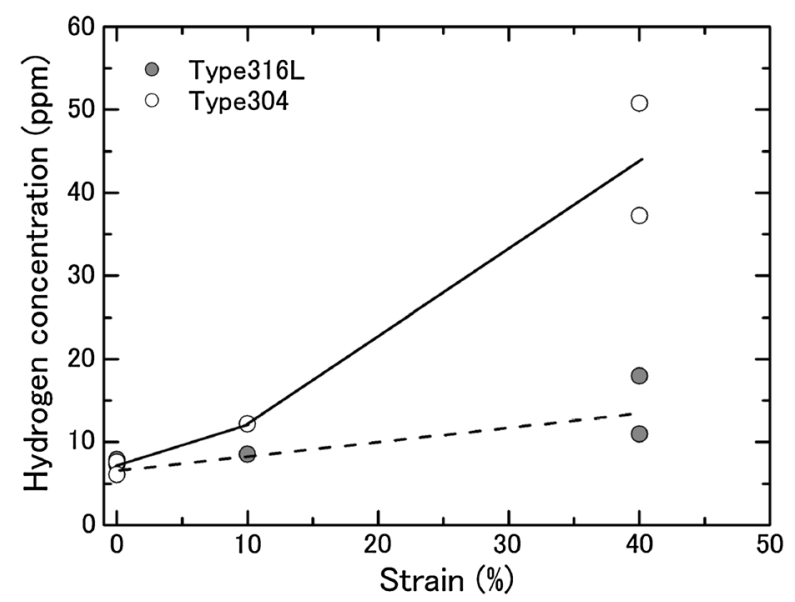

Fig. 11-Variation with tensile strain of peak area of cathodically charged Type 304 and $316 \mathrm{~L}$ steels. reproduce TDA peaks quite well in Type 304 and 316L specimens, respectively, while the other diffusivities (S-K and $\mathrm{T}-\mathrm{I}$ ) both predict higher peaks at lower temperatures.

Figure 13 compares calculated and experimental TDA spectra in Type 304 steel charged under Condition 2. The surface concentration of hydrogen was adjusted to $71 \mathrm{ppm}$ so that the peak area matches that of experimental peak. As mentioned above, the experimental

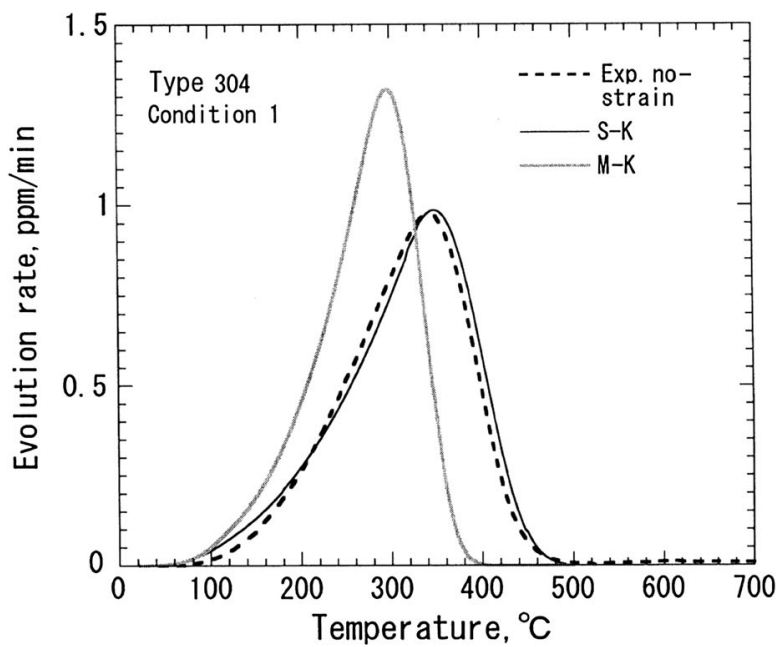

(a)

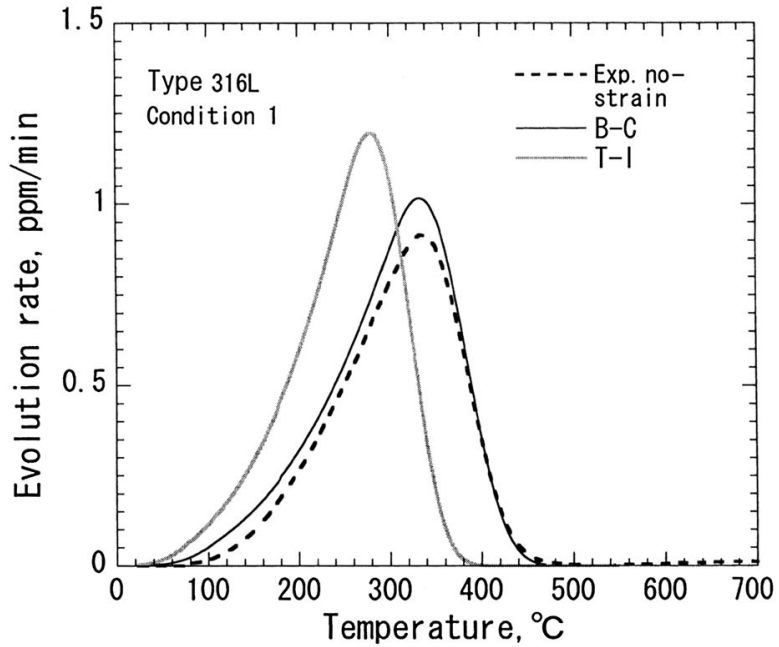

(b)

Fig. 12-Comparison of calculated and experimental TDA spectra of (a) Type 304 and (b) Type $316 \mathrm{~L}$ without pre-strain, exposed to hydrogen atmosphere of $98 \mathrm{MPa}$ at $250{ }^{\circ} \mathrm{C}$ for $72 \mathrm{~h}$ (Condition 1). The surface concentration of hydrogen was assumed to be $100 \mathrm{ppm}$.

Table III. Diffusivities of Hydrogen Used in McNabb-Foster Simulations

\begin{tabular}{lcccc}
\hline Alloy & Deformed or Non-deformed & $D_{0}\left(\mathrm{~m}^{2} / \mathrm{s}\right)$ & $Q(\mathrm{~kJ} / \mathrm{mol})$ & $\mathrm{Reference}$ \\
\hline Type 304 & non-deformed & $4.41 \times 10^{-7}$ & 53.51 & \\
& deformed & $4.51 \times 10^{-7}$ & 49.9 & {$[15]$} \\
nype 316L & non-deformed & $1.21 \times 10^{-5}$ & 63.1 & {$[15]$} \\
& non-deformed & $6.2 \times 10^{-7}$ & 53.63 & {$[16]$} \\
\hline
\end{tabular}




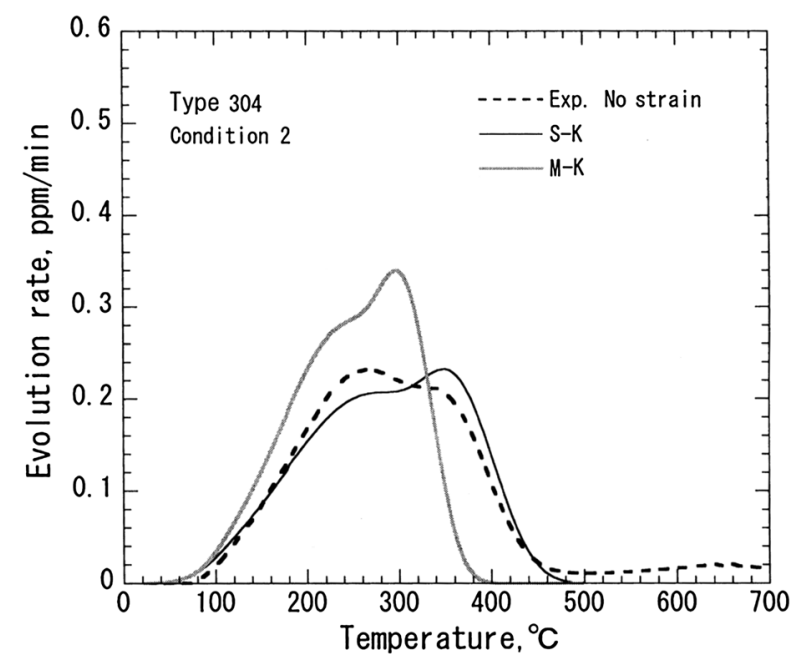

Fig. 13-Comparison of calculated and experimental TDA spectra of Type 304 without strain, charged under Condition 2. The surface concentration of hydrogen was assumed to be $71 \mathrm{ppm}$.

spectrum appears as if two peaks were overlapping, the left peak lying at $523 \mathrm{~K}\left(250^{\circ} \mathrm{C}\right)$, considerably lower than that found under Condition 1 (Figure 12(a)). These features are reproduced well in the simulation in which no trap sites were assumed. Figure 14(a) shows the hydrogen profile prior to temperature ramp, i.e., in the as-charged specimen. In contrast to Condition 1 , the hydrogen concentration is not uniform, only $\sim 20$ pct of the surface concentration (denoted $c_{\mathrm{s}}$ hereafter) in the central region. In order to see the reason why the peculiar TDA spectrum shape mentioned above was formed, the variation of hydrogen concentration profile with time during heating is calculated in Figure 14(b). It is seen that hydrogen near the outside of the specimen quickly desorbed from the surface, which may have formed the first peak at a lower temperature. At the same time, a substantial fraction of hydrogen diffused inward and came back to the surface later to form the second higher temperature peak. The TDA spectrum of Type 316L steel (Figure 8(b)) can also be explained in this way. The shape and relative heights of the first and second peaks may vary with the diffusivity of hydrogen and presumably with charging time.

\section{B. Specimen Without Tensile Strain Charged Under Cathodic Electrolysis}

Figure 15 compares simulated TDA spectra for Type 304 steel specimens which were cathodically charged in the unstrained condition. In order to match the peak area of the experimental spectrum, the surface concentration of hydrogen was determined to be very high $(510 \mathrm{ppm})$, as expected in cathodic charge. ${ }^{[19]}$ The temperature at the peak hydrogen evolution rate was relatively low $\left[\sim 373 \mathrm{~K} \quad\left(\sim 100^{\circ} \mathrm{C}\right)\right]$, and this peak temperature is reproduced very well by calculations using both the reported $\mathrm{S}-\mathrm{K}$ and $\mathrm{M}-\mathrm{K}$ diffusivities (Figure 10(b)). Such a low peak temperature was also obtained in cathodically charged Type $316 \mathrm{~L}$ specimens. Clearly, these low gas evolution peak temperatures are

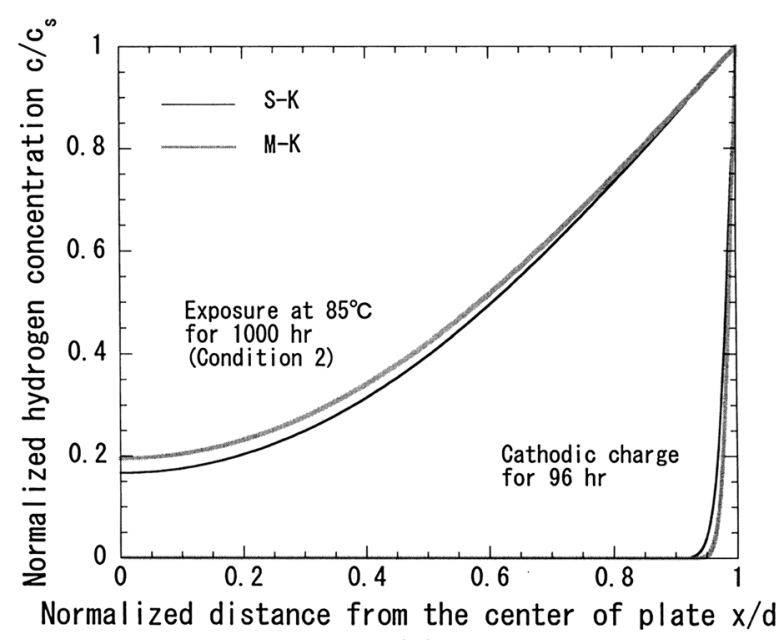

(a)

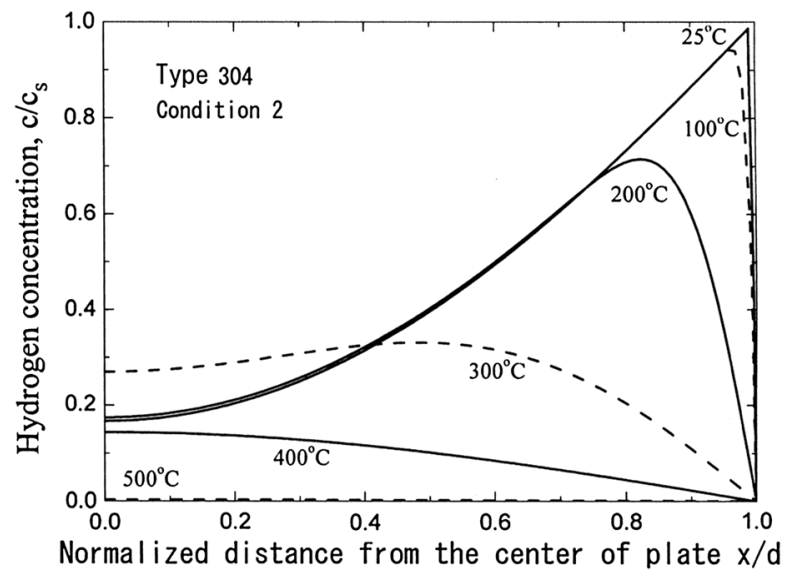

(b)

Fig. 14 - (a) Diffusion penetration curves in the as-charged condition calculated with two diffusivities in type 304 steel without pre-strain, charged under Condition 1 and 3. (b) Calculated evolution during TDA of hydrogen profile in Type 304 charged under Condition 2. The ramp rate is $100 \mathrm{~K} / \mathrm{h}$.

the consequence of the initial hydrogen distribution confined to the narrow peripheral region of the specimen shown in Figure 14(a) (cathodic charge). Almost all hydrogen in the peripheral region desorbed quickly from the surface at an early stage, thus forming a single desorption peak at a lower temperature.

Takai et al. ${ }^{[12]}$ reported that the peak temperature and shape of TDA spectra of Type 316L steel became very similar irrespective of charging method if the temperature and time of hydrogen charge were the same and sufficiently long. The present results indicate that TDA spectra in stainless steels, both peak temperature and shape, depend very much on the condition of hydrogen charge, or more specifically the initial distribution of hydrogen in the specimen. When hydrogen is distributed uniformly prior to temperature ramp, one broad peak appears above $623 \mathrm{~K}\left(350^{\circ} \mathrm{C}\right)$. If the initial distribution is confined to the narrow peripheral region of the specimen, a peak appears at a temperature as low as $373 \mathrm{~K}\left(100{ }^{\circ} \mathrm{C}\right)$. An initial distribution between these two extreme cases can cause a broad peak with humps, ranging from $473 \mathrm{~K}$ to $673 \mathrm{~K}\left(200{ }^{\circ} \mathrm{C}\right.$ to $\left.400{ }^{\circ} \mathrm{C}\right)$, and 


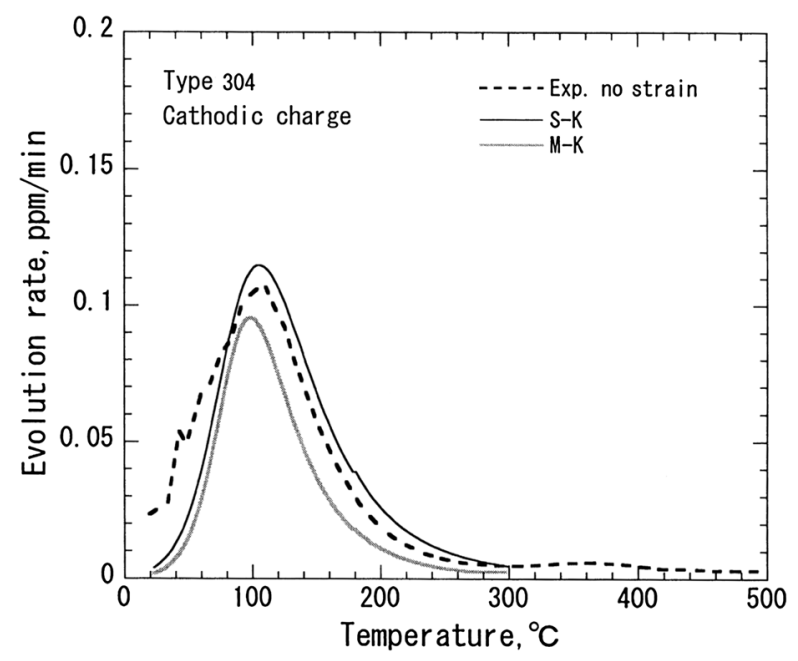

Fig. 15-Comparison of calculated and experimental TDA spectra of cathodically charged Type 304 without pre-strain (Condition 3). The surface concentration of hydrogen was assumed to be $510 \mathrm{ppm}$.

the whole peak often appears as if more than one peak is overlapped.

\section{Effects of Deformation on TDA Spectrum}

Maroef et al. compiled the binding energies hydrogen at various trap sites, e.g., dislocation, grain boundary, oxide and carbide interfaces, etc., in ferritic steel. ${ }^{[20]}$ Compared to ferritic steel, much less data are available for austenitic steel. Atrens and Fiore ${ }^{[21]}$ reported the binding energy of hydrogen at dislocation in Type 310 stainless steel $\left(E_{\mathrm{B}}=13.5 \mathrm{~kJ} / \mathrm{mol}\right)$ using a dislocation-damping experiment. This binding energy is considerably smaller than that in bcc iron $\left(E_{\mathrm{B}}=42 \mathrm{~kJ} /\right.$ $\left.\mathrm{mol}^{[22]}\right)$. Thus, in austenitic steel, the amount of hydrogen trapped by dislocations can be less than that dissolved in the lattice. Mine et al. ${ }^{[23]}$ reported that the amount of hydrogen trapped by grain boundary can be neglected in Type 310S stainless steel in which the grain size was refined to less than $100 \mathrm{~nm}$ by high-pressure torsion. This also seems to be the case with the present alloys because the grain size was much greater (13 to $15 \mu \mathrm{m})$. Furthermore, in the alloys studied, a low concentration of oxide inclusions or carbides is likely to be present because the specimen alloys were annealed at a high temperature. Hence, dislocations are assumed to be the primary hydrogen trap sites in the simulation of TDA spectra of specimens with tensile strain. Shintani and Murata ${ }^{[24]}$ reported that the dislocation density does not exceed $5.0 \times 10^{14} \mathrm{~m}^{-2}$ with increasing strain in Type 304 stainless steel. In fcc iron, hydrogen occupies the octahedral interstitial sites. Since the number of octahedral interstitial sites is equal to the number of $\mathrm{Fe}$ atoms, the number of occupation sites is evaluated to be 5 to 10 per Fe atom plane if hydrogen occupies the octahedral sites within the distance of two times the Burgers vector from the dislocation core. It is also assumed that local equilibrium was achieved between the lattice and the trap sites, which requires that $p_{0}$ is equal to $10^{8} \mathrm{~s}^{-1}$ or greater.

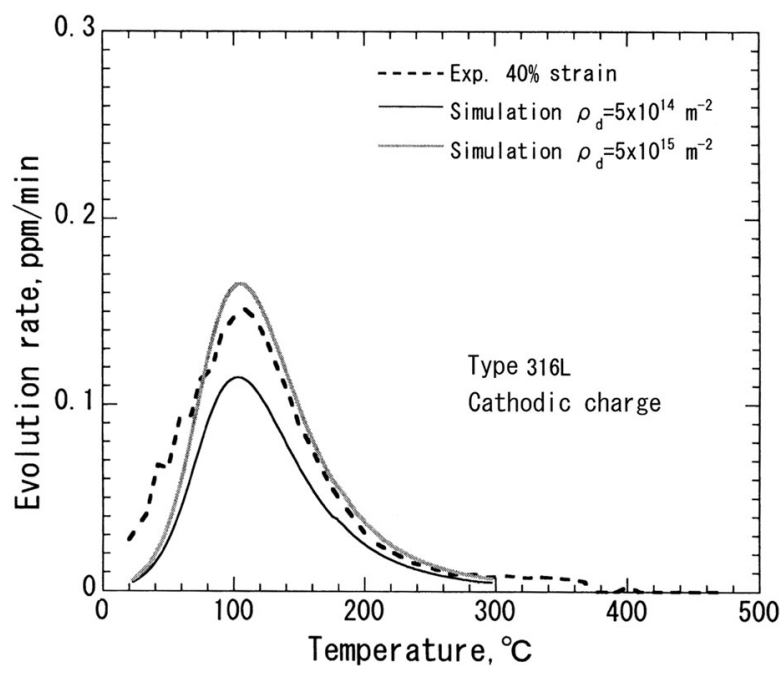

Fig. 16-Comparison with experiment (dashed curve) of TDA spectra of cathodically charged Type $316 \mathrm{~L}$ with 40 pet strain calculated assuming the dislocation density of $\rho_{\mathrm{d}}=5 \times 10^{14}$ and $5 \times 10^{15} \mathrm{~m}^{-2}$. The surface concentration of hydrogen was assumed to be $550 \mathrm{ppm}$.

With these parameters, the TDA spectrum of cathodically charged Type $316 \mathrm{~L}$ specimen with 40 pct strain was simulated as shown in Figure 16. No appreciable influence of hydrogen trapping at dislocations was observed in the spectrum until the dislocation density was increased to $5 \times 10^{15} \mathrm{~m}^{-2}$. As long as the dislocation density reported by Shintani and Murata ${ }^{[24]}$ is assumed, the trap site of the excess amount of hydrogen is not clear. Dislocation kinks and/or vacancies formed upon the intersection of dislocations could serve as additional trap sites.

In Figure 6(b), the peak temperature decreased slightly in the 40 pct strained specimen compared to non-strained and 10 pct strained Type 316L specimens. This was presumably caused by pipe diffusion of hydrogen along dislocations at a high hydrogen concentration.

As shown earlier, the effects of pre-strain in Type 304 steel are very different from those in Type 316L steel; the TDA spectrum area of 40 pct pre-strained specimen decreased under Condition 1, while it increased remarkably when specimens were exposed to hydrogen under Condition 2 or through cathodic charging. The solubility of hydrogen in ferrite is considerably smaller than that in austenite. ${ }^{[25]}$ Recently, it is observed that the amount of absorbed hydrogen does not exceed a few ppm in Type 420 martensitic stainless steel after prolonged exposure at high pressure. ${ }^{[26]}$ From the XRD spectrum in Figure 3, the volume fraction of martensite was evaluated to be in the range of 0.21 to $0.28 .^{[27]}$ Indeed, it is reported that ca. 20 pct of the austenite matrix transformed to martensite upon tensile deformation in Type 304 steel. $^{[28]}$ Moreover, according to Shintani and Murata, ${ }^{[24]}$ the fraction of martensite was 50 to 60 pet in 40 pct cold rolled Type 304 steel. Thus, the decrease in the TDA spectrum area of the $40 \mathrm{pct}$ strained Type 304 steel (Figure 7) is primarily due to the formation of strain-induced martensite. 


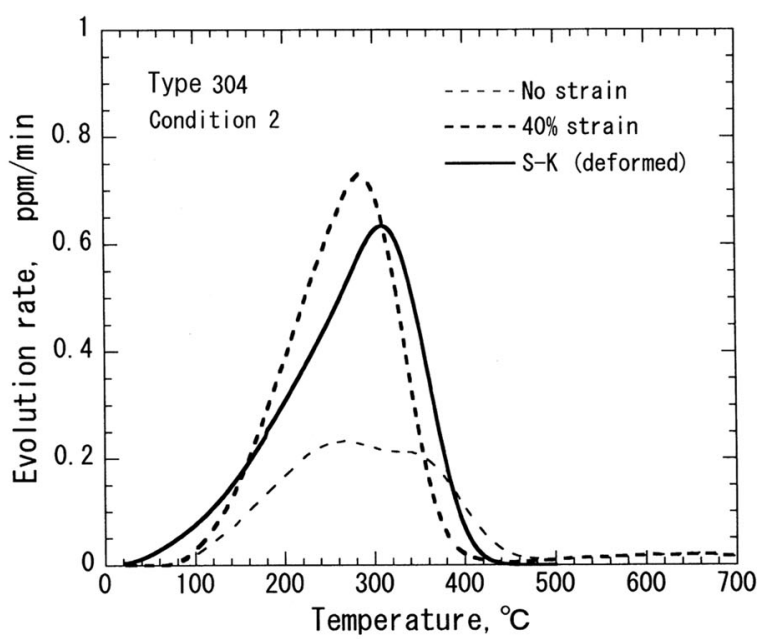

(a)

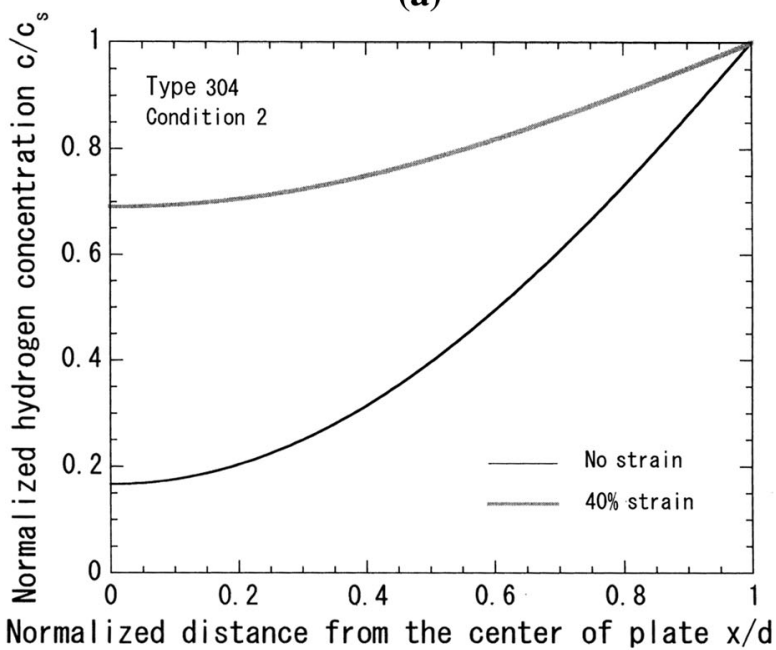

(b)

Fig. 17-(a) Comparison of calculated and experimental TDA spectra of Type 304 with 40 pct strain exposed to high-pressure atmosphere at $358 \mathrm{~K}\left(85^{\circ} \mathrm{C}\right)$ for $1000 \mathrm{~h}$ (Condition 2). Thin and thick dashed curves were calculated using the diffusivity reported by $\mathrm{Sa}$ kamoto and Katayama for non-deformed and deformed specimens. The surface concentration of hydrogen was assumed to be $81 \mathrm{ppm}$. (b) Diffusion penetration curves in the as-charged condition calculated in Type 304 with 40 pct strain and without strain, charged under Condition 2.

Sakamoto and Katayama ${ }^{[15]}$ reported that the diffusivity of hydrogen in deformed Type 304 steel increased by a factor of 3 to 5 from that without deformation. They ascribed this increase in effective diffusivity to the formation of strain-induced martensite, which can serve as a high-diffusivity path for hydrogen at a high hydrogen concentration. Figure 17(a) compares with experiment the calculated and experimental TDA spectra of Type 304 specimen with 40 pet strain charged under Condition 2. In Figure 17(b), the diffusion penetration curves are shown for the same specimen in the as-charged specimens with and without deformation. Thus, the marked increase in peak area can be attributed to the increase in effective diffusivity due to the formation of martensite. This can also account for the large increase in the TDA spectrum area in the cathodically charged specimen with 40 pct strain (Figure 10(a)). The absence of a peak around $373 \mathrm{~K}$ $\left(100^{\circ} \mathrm{C}\right)$ reported in martensitic steel ${ }^{[29]}$ is possibly attributed to the fact that strain-induced martensite crystals are embedded in austenite in which the hydrogen diffusivity is much slower than in martensite.

\section{CONCLUSIONS}

Hydrogen absorption during cathodic charging and exposure to high-pressure gaseous hydrogen were studied in Type 316L and 304 stainless steels by means of TDA in an attempt to establish the relationship between the conditions of the two different hydrogen charging methods. TDA spectra were simulated by the McNabbFoster model to analyze the difference in the spectrum shape and peak gas evolution temperature between the two steels and the effects of charging temperature, time, and pre-deformation strain. The results are summarized as follows.

1. Both Type 316L and Type 304 steels without tensile strain, which were exposed to high-pressure gaseous hydrogen at $523 \mathrm{~K}\left(250{ }^{\circ} \mathrm{C}\right)$ for 72 hours, exhibited a large gas evolution peak above $573 \mathrm{~K}\left(300^{\circ} \mathrm{C}\right)$, while those exposed to high-pressure gaseous hydrogen at $358 \mathrm{~K}\left(85^{\circ} \mathrm{C}\right)$ for 1000 hours exhibited a flat and broad peak ranging from $473 \mathrm{~K}$ to $673 \mathrm{~K}$ $\left(200{ }^{\circ} \mathrm{C}\right.$ to $\left.400{ }^{\circ} \mathrm{C}\right)$. The peak appeared as if it consisted of closely lying two peaks. The simulation indicated that hydrogen penetrated fully into the specimen in the former condition, while it did only partially in the latter condition. Simulation also revealed that nearly a half of hydrogen in the specimens exposed to hydrogen at the lower temperature condition quickly desorbed at the surface, and the other remaining portion diffused toward the interior of the specimen and then returned to the surface to form a second flat broad peak in the gas evolution rate, which produced two peaks in the TDA spectra.

2. Both steels cathodically charged at ambient temperature exhibited a peak in hydrogen gas evolution at approximately $373 \mathrm{~K}\left(100{ }^{\circ} \mathrm{C}\right)$. According to the simulation, the initial hydrogen distribution was confined to the narrow peripheral region of the specimen.

3. Tensile strain exhibited only a marginal increase in the amount of hydrogen in Type 316L steel, both cathodically charged and exposed under high-pressure hydrogen atmosphere. The simulation using the reported dislocation density and the binding energy of hydrogen in fcc iron did not have an appreciable effect on the amount of hydrogen, and thus lend support to the observed absorption behavior in this steel.

4. Tensile strain increased the amount of absorbed hydrogen from high-pressure hydrogen gas at $358 \mathrm{~K}\left(85^{\circ} \mathrm{C}\right)$ in Type 304 steel, while it decreased significantly the amount of hydrogen absorbed from high-pressure hydrogen gas at $523 \mathrm{~K}\left(250^{\circ} \mathrm{C}\right)$. The 
tensile strain also markedly increased the amount of hydrogen in the same steel cathodically charged at ambient temperature. These are likely to be caused by strain-induced martensitic transformation, which has a lower hydrogen solubility and faster hydrogen diffusivity than in austenite.

These results indicate that the initial distribution of hydrogen prior to the TDA has a large influence on the spectrum shape and peak hydrogen gas evolution temperature. Moreover, one can predict the absorption of hydrogen under high-pressure atmosphere at elevated temperatures from that under cathodic charge as long as the surface concentration of hydrogen or effective hydrogen fugacity at the specimen surface is available.

\section{ACKNOWLEDGMENTS}

The authors express their sincere thanks to the members of forum of building fundamental platform for research of $\mathrm{HE}$, sponsored by The Iron and Steel Institute of Japan, Tokyo.

\section{REFERENCES}

1. Hydrogen Energy White paper, New Energy and Industrial Technology Development Organization, Tokyo, 2014. http:/ www.nedo.go.jp/library/suiso_ne_hakusyo.html?from $=$ b. Accessed 16 Oct 2014.

2. H.R. Gray: ASTM STP543, 1974, pp. 133-51.

3. R.P. Jewett, R.J. Walter, W.T. Chandler, and R.P. Frohmbert: NASA CR-2163, 1973.

4. W.T. Chandler and R.J. Walter: ASTM STP543, 1974, pp. 170-97.

5. G. Han, J. He, S. Fukuyama, and K. Yokogawa: Acta Mater., 1998, vol. 46, pp. 4559-70.

6. D. Sun, G. Han, S. Vaodee, S. Fukuyama, and K. Yokogawa: Mater. Sci. Technol., 2001, vol. 17, pp. 302-08.

7. H. Nakagawa: Proc. ASME Pressure Vessels \& Piping Conference 2007, Paper No. PVP2007-26462, 2007.
8. T. Ohmura, M. Miyahara, H. Semba, M. Igarashi, and H. Hirata: Proceedings of ASME Pressure Vessels \& Piping Conference 2007, Paper No. PVP2007-26496, 2007.

9. S. Ohmiya and H. Fujii: Proceedings of ASME Pressure Vessels \& Piping Conference 2007, Paper No. PVP2007-26492, 2007.

10. S. Fukuyama, M. Imade, and K. Yokogawa: Proceedings of ASME Pressure Vessels \& Piping Conference 2007, Paper No. PVP2007-26820, 2007.

11. T. Omura, K. Kobayashi, M. Miyahara, and T. Kudo: Zairyo-toKankyo, 2006, vol. 55, pp. 537-43 (in Japanese).

12. K. Takai, K. Murakami, N. Yabe, H. Suzuki, and Y. Hagihara: $J$. Jpn. Inst. Met., 2008, vol. 72, pp. 448-56.

13. A. McNabb and P.K. Foster: Trans. TMS-AIME, 1963, vol. 227, pp. 618-27.

14. A. Turnbull, R.B. Hutchings, and D.H. Ferriss: Mater. Sci. Eng. A, 1997, vol. 238, pp. 317-28.

15. Y. Sakamoto and H. Katayama: J. Jpn. Inst. Met., 1982, vol. 46, pp. 805-14.

16. Y. Mine and T. Kimoto: Corros. Sci., 2011, vol. 53, pp. 2619 29.

17. A.-M. Brass and J. Chêne: Corros. Sci., 2006, vol. 48, pp. 3222 42.

18. T. Tanabe and S. Imoto: Proc. Int. Symp. Hydrogen in Metals, Supplement to Trans., JIM, vol. 21, 1980, pp. 109-12.

19. R.A. Oriani and P.H. Josephic: Acta Metall., 1979, vol. 17, pp. 997-1005.

20. I. Maroef, D.L. Olson, M. Eberhart, and G.R. Edwards: Int. Mater. Rev., 2002, vol. 47, pp. 191-23.

21. A. Atrens, N.F. Fiore, and K. Miura: J. Appl. Phys., 1977, vol. 48, pp. 4247-51.

22. S. Taketomi, R. Matsumoto, and N. Miyazaki: Acta Mater., 2008, vol. 56, pp. 3761-69.

23. Y. Mine, Z. Horita, and Y. Murakami: Acta Mater., 2010, vol. 58, pp. 649-57.

24. T. Shintani and Y. Murata: Acta Mater., 2011, vol. 59, pp. 4314 22.

25. A. San-Martin and F.D. Manchester: in Phase Diagrams of Binary Iron Alloys, H. Okamoto, ed., ASM International, Materials Park, 1993, pp. 161-70

26. T. Ohmura: Unpublished research at Nippon Steel \& Sumitomo Metal Corporation, 2014

27. A. Etienne, B. Radiguet, C. Genevois, J.-M. LeBreton, R. Valiev, and P. Pareige: Mater. Sci. Eng. A, 2010, vol. 527, pp. 5805-10.

28. E. Ishimaru, H. Hamasaki, T. Ohno, and F. Yoshida: J. Jpn. Soc. Technol. Plast., 2014, vol. 55, pp. 615-19.

29. M. Enomoto, D. Hirakami, and T. Tarui: ISIJ Int., 2006, vol. 46, pp. 1381-87. 